\title{
Health status and health disparity in China: a demographic and socioeconomic perspective
}

\author{
Jianye Liu ${ }^{1}$ (D) $\cdot$ Yiqiao Zhang ${ }^{1}$ \\ Received: 15 June 2018 / Accepted: 10 September 2018 / Published online: 20 September 2018 \\ (c) Springer Nature Singapore Pte Ltd. 2018
}

\begin{abstract}
Using Chinese General Social Survey (CGSS) in 2005, 2008 and 2013, this study investigates health determinants and health inequality in China. The ordinal complementary log-log model is used firstly to examine the impact of individual and contextual factors on self-rated health status. The study further checks the health inequality among subgroups divided by health determinants considered in the determinant model. We find that there are significant gender, residential, ethnic, socioeconomic, emotional, regional, and periodic differences. Moreover, the health status of sub-groups defined by factors used in this research is affected by health determinants in different ways which indicates the impact of these health determinants on health is moderated by each other. We conclude that while the health status generally varies with individual factors and social contexts, each group characterized by individual and contextual features has its own unique needs to improve and maintain their health status in China. The public policies aiming to increase Chinese health status and reduce health inequality must pay close attention to these needs while equalizing the availability, accessibility, and affordability of health facilities and health care system.
\end{abstract}

Keywords Health status $\cdot$ Health disparity $\cdot$ Health determinants

\section{Introduction}

The general health status of human being has improved significantly with the socioeconomic development, advances in medical science, and the increase of living standard (Rao 2004). However, the health disparity still widely exists in mortality, morbidity, life expectancy and health services by gender, occupation, ethnicity,

Jianye Liu

jliu8@lakeheadu.ca

1 Sociology Department, Lakehead University, 955 Oliver Road, Thunder Bay, ON P7B 5E1, Canada 
employment status, region, and so on (Macintyre 1997; Braveman and Tarimo 2002).

In China, while the life expectancy is above the world average (World Health Organization 2016), the health disparity is significant. For instance, the maternal and child mortality rate in rural areas is 2.5 times that of those in urban areas and the maternal mortality rate is 10 times higher in the poorest province than it in the richest one (Xi et al. 2014) and the gap in life expectancy between these two provinces is as high as 13 years (Bai 2008). Therefore, the health disparity is an urgent social problem that is hidden behind the overall improvement of health.

Since the social and economic reform in the early 1980s, China has started a transformation from a planned-economy to a market one and the overall socioeconomic development has been remarkable. The reform in the medical area is mainly to transform medical resources like doctors and funding from two lower tiers of the original three-tier medical system (local doctors and clinics), to the highest one, hospitals in the medium or large cities, where the quality of the medical services is much better than those in rural areas. One direct consequence of the medical reform in China is the increase of the medical expenditure and difficulty of accessing medical services which enlarges the health disparity in China, including disparity between gender and residence (urban VS rural areas), among people with different income levels, and so on, because of the increasing disparity in availability, accessibility, affordability, and quality of health care (Liu and Gu 2011). In the meantime, the health insurance reform and the marketization of the service industry in China have profoundly impacted the entire population and low-income and rural residents in particular (Xie 2009). For example, Gao et al. (2002) examine the impact of economic transformation and health system reform on health and health equity in China in the 1990s (1990-1998) and find that although mortality declines in both urban and rural areas, the income gap between them continues to widen, and so is the accessibility of health care services. Using data from the Statistical Yearbook, Zhang (2003) further confirms the intensified health disparity in China and argues that the urban-focused policy in the process of reform plays an important role in this trend. Xie (2009) finds that the health equality was fairly high in the 1990s, and health is becoming more and more unequal in China with the social and economic reforms. In addition, using Self Rated Health (SRH) as the measure of health status, Qi and Li (2011) confirm the deterioration of health equality between 1991 and 2006. In sum, with the improvement of overall health in China, the health disparity is getting worse due to enlarging regional differences in income, availability, accessibility, affordability, utilization of healthcare service, and health care coverage and quality.

The research on health determinants and health disparity in China is still at the initial stage. This study try to examine health determinants and health disparity in China through a systematic and comprehensive analysis of China General Social Survey (CGSS) data in 2005, 2008 and 2013. 


\section{Health, health disparity and measurement}

Health status is one of the most important indicators of human welfare and an indicator of life quality. From the individual perspective, a healthy body has both instrumental value (more labor capability, more productivity, which leads to higher income) and intrinsic value (happier) (Wang and Liu 2005; Sen 1980; Zhang 2003; Wei 2004). From a national perspective, a healthy population is an important resource for socioeconomic development (Fogel 1994; Barro 1996; Liu et al. 2004). On the other hand, the unhealthiness weakens people's capability to create wealth, reduces their quality of life, and eventually, forces them fall into the vicious circle of "unhealthy-poverty-unhealthy" (Fan 2002).

The definition and measurement of health is a controversial and complex issue. From an economic perspective, Sen (1980) proposes that health is a primary "capability" of human beings, the basic resource of building wealth, and a kind of "freedom" of being human. Based on Sen's proposal, United Nations Development Program (UNDP 1990) has defined health as one of three primary goals of human development in their "Human Development Index".

Because of the complexity, a variety of measures have been used to examine individuals' health status, which can be generally divided into objective and subjective measurements. Objective measurements such as mortality and morbidity are usually the most commonly used and normally accurate and reliable, but they only assess the biological aspect of health. Subjective measurements such as Activities of Daily Living (ADL) and Self-Rated Health (SRH) reflect more general aspects of health, including both social and psychological aspects. ADL is commonly used to study recovering patients and SRH is widely used in health research for the general population.

According to Wilkinson (1996), SRH is a good measure of general health as it is able to foresee mortality rate without using any social and/or economic factors. For instance, SRH is usually more objective than other health measures in research on seniors (Maddox and Douglas 1973). Moreover, SRH is highly correlated with health professional judgement and severity level of disease at both individual and group levels (Ferro 1980; Maddox and Douglas 1973; Ahn et al. 2010). For instance, Elstad and Krokstad (2003) find that SRH can effectively predict the mortality, loss of function, morbidity and other objective health measurement indicators. In the current health study in China, the SRH status is commonly used as a measure of individual health (Wang 2011, 2012). We will use SRH to measure health status in China in this study as it has been consistently collected in CGSS since 2005.

\section{Theoretical framework: health determinants and health disparity}

In Grossman's model, health is treated as a capital good, which can be built up by investment or run down by the lack of investment (Grossman 1972). The model goes beyond traditional demand analysis and considers the individual as both a 
producer and consumer of health. That is, health, as an output, can be improved through investing in human capital such as medical care, social status, work environment, employment status, income, housing conditions, education, diet, lifestyle and so on in both the market (work) and non-market (household) sectors (Wang and Liu 2005; Wagstaff et al. 2003). Consequently, the disparity in health is caused by the variation of these factors among individuals and social contexts.

Compared to other countries, health disparity in China is higher, gendered, more income-related, and quite different across regions (Hu 2005; Liu 2009; Liu and Chao 2009: Wang et al. 2003; Deng 2010; Xie 2009). Gender differential in health is widely observed in China (Cui and Li 2009). In China, because of Confucianism and patriarchal system, husbands play a leading role in the economy, and wives play a leading role in the housework. Husbands benefit from their wives' housework, while wives normally have the double burden of working inside and outside the household. In general, husbands are the beneficiaries of marriage, and wives are the providers of services within marriage. It is this different gender role that causes marriage to have a different effect (health and longevity) on the health status of husband and wife. Based on China Health and Nutrition Survey (CHNS) 2000 data, Sun and Song (2008) find that men's health status is better than that of women, with the largest gender differences in the middle class.

Health is significantly associated socioeconomic status which is normally a combined measure of a person's income, education, and occupation (Wang et al. 2003). The socioeconomic status affect health status through lifestyle, that is, people with higher socioeconomic status are more likely to afford and maintain a healthy lifestyle due to their economic or cultural capital (Wang 2012). Lee and Jones (2007) examine the income-related health disparity and find health disparities in both overall physical and mental health which favor the rich. According to their research, income itself explains $40 \%$ to $73 \%$ of general and mental health disparity in all regions, education explains 15-22\% general health disparity, and employment status explains $17-18 \%$ of mental health disparity. At the provincial level, using CHNS data from 1991 to 2000, Hou (2007) finds that income plays an increasingly important role in health and provinces with lower socioeconomic status are more likely to have a lower health status on average.

Moreover, there are significant regional health differences in China (Zhao 2005; Allison and Foster 2004). In general, with the order of Western region, Northeastern region, Central region, Municipalities, and Eastern region, the average health status as a whole is increasing. For instance, Li et al. (2004) find that compared to those living in the Eastern or Coastal area, the health status of those in Western region is significantly lower. Liu et al.'s later study (2006) show that there is a significant healthy gap between the Eastern and Western regions and this regional health difference increases slightly between 1990 and 2000. Comparing to the rural area, the urban area is better in health as a whole. Liu and Chao (2009) find that regional economic development and income distribution are important factors in regional health disparity. For instance, the income-related health inequalities are more significant among rural residents instead of urban ones (Wang et al. 2003; Xie 2009). The authors argue that health disparity will continue to worsen in the context of increased disparity in income and the reform in the health care systems. Liu and $\mathrm{Hu}$ 
(2002) find that the gap in health between urban and rural residents during the transition period (1985-1993) is widening, which is associated with the increasing gap between them in income and health care facilities as a direct consequence of reform in health in China, including a significant decline in the coverage of rural population insurance and the government's support of public health.

Furthermore, marital status is also a very important determinant of health. Existing literature shows that married people are more likely to have a better health because of the selectivity and protection of marriage. The selectivity of marriage means that healthy people are more likely to be selected in the marriage market compared to those unhealthy ones. The protection of marriage infers that marriage can offer married members a healthy social, psychological, and physical environment including the supervision of the spouse and the social support from family members, which may promote a healthy lifestyle. In other words, marriage provides resources like emotional and social support, companion, and so on, needed in promoting mental and physical health (Schoen and Weinick 1998; Allen 1994; Waite 1995). In the meantime, the dissolution of a marriage like separation, divorce, or death of the partner can deteriorate health conditions of the living partner (Burkhauser and Duncan 1991).

In addition to the above factors, age and lifestyle are also important contributors to health disparity. Traditional research tends to study the role of these socioeconomic factors in health and pay less attention to the interaction of these factors. In this study, the health disparity is examined by testing whether the health status of people characterized by some demographic and socioeconomic factors are affected by the health determinants discussed above in different ways.

\section{Data and method}

The data sets used in this study are from the CGSS. The CGSS, launched in 2003, is used to systematically monitor the changing social structure and quality of life in China. Using a multistage, stratified and random cluster sampling design, respondents were selected from 28 provinces (out of 33 provincial-level administrative divisions) of China.

The CGSS data sets are used in this study because the CGSS is the first national representative surveys in mainland China. Moreover, it contains a significant amount of information on the demographics, health status, and socioeconomic indicators of individuals, which can satisfy the information needed for this research project. Furthermore, most of the needed information is measured consistently across all surveys. CGSS in 2005, 2008 and 2013 have been used in this study and the total number of valid cases is 25,254 .

\subsection{Dependent variable}

The dependent variable used in this study, health status, is measured by SRH which has been collected in the same way in CGSS since 2005. The SRH is measured by 
question, "What do you think about your health condition?" with five categories (very $\operatorname{bad}=1$; $\operatorname{bad}=2$; normal $=3$; good $=4$; very good $=5$ ). Respondents answer this question based on their subjective assessment of their current health status, which is a comprehensive evaluation of their health condition, including both physical and mental problems.

\subsection{Independent variables}

Health status can be affected by many genetic, biological, psychological, and social factors. Variables examined in this study include gender (male; female, the reference group), age (age of the respondents in the corresponding survey year, 18-98), residential place (urban; rural, the reference group), ethnic group (Han; minorities, the reference group), family income (low income; mid-low income; middle income; mid-high income; and high income, the reference group), education level (uneducated; primary/middle school; high school; college or higher, the reference group), marital status (never married; married/common-law; ever married (divorced, separated, and widowed, the reference group), survey year (2005; 2008; 2013, the reference group), regions (Northeastern region; Eastern region; Central region; Western region; Municipalities (including Beijing, Shanghai, Tianjing, and Chongqing), the reference group), socioeconomic status (SES, an index created by a factor analysis of income and education level).

\subsection{Methodology}

Because of the ordinal nature of the measurement and higher categories are more probable in the distribution of the dependent variable (see Table 1), an ordinal complementary log-log model is used. That is,

$$
P(y \leq i \mid \boldsymbol{X})=\exp \left(-\exp \left(\alpha_{i}-\beta \boldsymbol{X}\right)\right)
$$

where $\alpha_{\mathrm{i}}$ is the threshold value (intercept for each category), $\beta_{\mathrm{i}}$ the coefficient, and $X$ the variable vectors.

The analytical method is used firstly to examine the impact of all independent variables listed above on the overall health status measured by SRH (SES is used in the determinant model because of the high correlation between income and education). We further divide the pooled data set into sub-samples by all health determinants used in this study and the same ordinal model is run for each sub-group to examine whether these variables affect the health status of these sub-groups in different ways.

\section{The determinants of health status in China}

The impact of each independent variable on SRH is shown in Table 2, which indicates that all variables in the model except marital status have a significant impact on people's SRH status. When all other variables in the model are controlled, males 
Table 1 Descriptive statistics of variables used in the study $(\mathrm{N}=25,254)$. Source: CGSS $(2005 / 2008 / 2013)$

\begin{tabular}{|c|c|c|}
\hline Variables & Frequency & Percentage \\
\hline \multicolumn{3}{|l|}{ Dependent variable } \\
\hline \multicolumn{3}{|l|}{ SRH status } \\
\hline Very bad & 600 & 2.4 \\
\hline $\mathrm{Bad}$ & 3290 & 13.0 \\
\hline Normal & 5561 & 22.0 \\
\hline Good & 9890 & 39.2 \\
\hline Very good & 5913 & 23.4 \\
\hline \multicolumn{3}{|l|}{ Categorical variable } \\
\hline \multicolumn{3}{|l|}{ Gender } \\
\hline Male & 12,406 & 49.1 \\
\hline Female & 12,848 & 50.9 \\
\hline \multicolumn{3}{|l|}{ Age } \\
\hline $18-29$ & 3899 & 15.4 \\
\hline $30-44$ & 8610 & 34.1 \\
\hline $45-59$ & 7545 & 29.9 \\
\hline $60+$ & 5200 & 20.6 \\
\hline \multicolumn{3}{|l|}{ Income level } \\
\hline Very low & 4481 & 17.7 \\
\hline Mid-low & 4783 & 18.9 \\
\hline Average & 5622 & 22.3 \\
\hline Mid-high & 5013 & 19.9 \\
\hline Very high & 5355 & 21.2 \\
\hline \multicolumn{3}{|l|}{ Education level } \\
\hline Uneducated & 2856 & 11.3 \\
\hline Primary/middle school & 13,577 & 53.8 \\
\hline High school & 5411 & 21.4 \\
\hline College or higher & 3409 & 13.5 \\
\hline \multicolumn{3}{|l|}{ Marital status } \\
\hline Single & 2584 & 10.2 \\
\hline Married & 20,539 & 81.3 \\
\hline Others & 2131 & 8.4 \\
\hline \multicolumn{3}{|l|}{ Region } \\
\hline Northeast region & 2977 & 11.8 \\
\hline Central region & 6289 & 24.9 \\
\hline Eastern region & 6358 & 25.2 \\
\hline Western region & 6071 & 24.0 \\
\hline Municipalities & 3559 & 14.1 \\
\hline \multicolumn{3}{|l|}{ Survey year } \\
\hline 2005 & 9682 & 38.3 \\
\hline 2008 & 5652 & 22.4 \\
\hline 2013 & 9920 & 39.3 \\
\hline
\end{tabular}


Table 1 (continued)

\begin{tabular}{|c|c|c|c|c|}
\hline Variables & \multicolumn{3}{|c|}{ Frequency } & Percentage \\
\hline \multicolumn{5}{|l|}{ Ethnic group } \\
\hline Han & \multicolumn{3}{|c|}{23,421} & 92.7 \\
\hline Minorities & \multicolumn{3}{|c|}{1833} & 7.3 \\
\hline \multicolumn{5}{|c|}{ Residential area } \\
\hline Urban & \multicolumn{3}{|c|}{12,309} & 48.7 \\
\hline \multirow[t]{2}{*}{ Rural } & \multicolumn{3}{|c|}{12,945} & 51.3 \\
\hline & $\operatorname{Max}$ & Min & Mean & Std. D \\
\hline \multicolumn{5}{|c|}{ Interval-ratio variable } \\
\hline SES & 49.30 & -1.46 & 0.00 & 1.00 \\
\hline Age & 98 & 18 & 45.94 & 15.17 \\
\hline
\end{tabular}

Table 2 The ordinal regression coefficient of variables on SRH

\begin{tabular}{|c|c|}
\hline Variables & Estimate \\
\hline \multicolumn{2}{|c|}{ Categorical variable } \\
\hline \multicolumn{2}{|c|}{ Gender $($ female $=$ ref $)$} \\
\hline Male & $0.202 * * *$ \\
\hline \multicolumn{2}{|c|}{ Ethnic group $($ minorities $=$ ref $)$} \\
\hline Han & $-0.097 * * *$ \\
\hline \multicolumn{2}{|c|}{ Residential area (rural = ref) } \\
\hline Urban & $0.034 *$ \\
\hline \multicolumn{2}{|c|}{ Marital status (others $=$ ref) } \\
\hline Single & 0.053 \\
\hline Married & 0.039 \\
\hline \multicolumn{2}{|c|}{ Region (municipalities $=$ ref) } \\
\hline Northeast region & $-0.125 * * *$ \\
\hline Central region & $-0.055^{*}$ \\
\hline Eastern region & $0.175 * * *$ \\
\hline Western region & $-0.149 * * *$ \\
\hline \multicolumn{2}{|c|}{ Survey year $(2013=$ ref $)$} \\
\hline 2005 & $-0.311 * * *$ \\
\hline 2008 & $-0.231 * * *$ \\
\hline \multicolumn{2}{|c|}{ Interval-ratio variable } \\
\hline Age & $-0.028 * * *$ \\
\hline SES & $0.081 * * *$ \\
\hline
\end{tabular}

and residents in the urban area have a better health status comparing to their corresponding reference groups, while Han people as a whole have a lower SRH than the other ethnic groups as a whole. Moreover, SRH declines with age, but increases with social economic status. From the regional perspective, comparing to residents 
in Municipalities (mainly urban and rich areas), those living in the relative poor regions (Northeast, Central, and Western regions) have a lower and those in the Eastern region, a rich region, have a higher health status. In term of periodical change of health status in China, it is clear that Chinese people's health status is generally getting better with time when all other variables in the model are controlled. However, marital status has no significant impact on health status, which is different from the previous literature which consistently indicates that married people normally have better health status than those who are single, separated, divorced, or widowed.

We may conclude that the health status in China is significantly associated with individual factors (age, gender, ethnicity, social economic status), social, economic, geographic contexts (residential areas, regions), and time (survey year). In the following session, the pooled three survey samples are divided into sub-groups by variables used in the determinant model and the health disparity is examined. To simplify the comparison among these sub-groups, only variables having different impacts on these sub-group's health status, which indicate health disparity, are displayed in tables and discussed in the text.

\section{Health disparity}

In this session, health disparity is explored by examining the impact of variables used in the determinant model on sub-groups' health status. There are in total nine variables are used in the sub-groups division including seven categorical variables in the determinant model. The two interval-ratio variables, age and SES, are categorized into three categorical variables. Age is divided into four groups, 18-29 (youth), 30-44 (young adult), 45-59 (adult), 60+ (seniors) (see Table 1). Two proxies of SES, education and income (per capita income), have four and five categories respectively (see Table 1 ).

\subsection{Health disparity by gender}

The total sample is firstly divided into two sub-samples by gender (see Table 3). There are four variables affect male and female's health status in different ways, ethnicity, residence, marital status, and region. Han male has a lower health status comparing to Minority male and no ethnic health difference among females, while female living in urban area has a better health status than those in rural area and no residential health difference among males. Moreover, though marital status has no significant effect on health status in the model with both male and female, never married male has a better health status comparing to his ever married counterpart while there is no significant marital health difference among females. Furthermore, the gender differential in health status only exists between the Central region and the reference group. Females, but not males, in the central region have significantly lower SRH than those living in Municipalities. This indicates that males living in Central region has a similar health status as those in mega cities. 
Table 3 The ordinal regression coefficient of variables on SRH by gender

\begin{tabular}{lcc}
\hline Variables & Male & Female \\
\hline Categorical variable & & \\
Ethnic group (minorities $=$ ref) & & \\
Han & $-0.177 * * *$ & -0.019 \\
Residential area (rural= ref) & & \\
Urban & 0.007 & $0.065^{* *}$ \\
Marital status (others $=$ ref) & & \\
Single & $0.104 *$ & -0.001 \\
Married & 0.034 & 0.038 \\
Region (municipalities $=\mathrm{ref})$ & & $-0.150^{* * *}$ \\
Northeast region & $-0.090^{*}$ & $-0.081^{*}$ \\
Central region & -0.023 & $0.161 * * *$ \\
Eastern region & $0.196 * * *$ & $-0.176^{* * *}$ \\
Western region & $-0.112^{* *}$ & \\
\hline$* * * \mathrm{p}<0.001 ; * * \mathrm{p}<0.01 ; * \mathrm{p}<0.05$ & &
\end{tabular}

\subsection{Health disparity by age}

The impacts of health determinants on the health status of different age groups are shown in Table 4. We can see that, when age is controlled in an experimental instead of a statistical way, ethnicity, region, and SES have different impacts on the health status of people in different life course. The ethnic health difference is only significant among young adults (aged 30-44). Secondly, the regional health difference is quite age-dependent. With significant regional differences observed in the determinant model in mind, it is interesting to see that youths in the Central and Eastern region, young adults in the Central region, adults in the Central and Western region, and seniors in the Northeast and Central region, have no significant health difference comparing to their corresponding reference groups.

Table 4 The ordinal regression coefficient of variables on SRH by age

\begin{tabular}{llccc}
\hline Variables & $18-29$ & $30-44$ & $45-59$ & $60+$ \\
\hline $\begin{array}{l}\text { Categorical variable } \\
\text { Ethnic group (minorities = ref) }\end{array}$ & -0.071 & $-0.109 *$ & -0.103 & -0.094 \\
$\quad$ Han & & & & \\
Region (municipalities = ref) & $-0.317 * * *$ & $-0.120^{*}$ & $-0.130^{* *}$ & -0.046 \\
$\quad$ Northeast region & -0.119 & -0.033 & -0.032 & -0.062 \\
Central region & -0.083 & $0.174 * * *$ & $0.302 * * *$ & $0.114 *$ \\
$\quad$ Eastern region & $-0.252^{* * *}$ & $-0.150^{* *}$ & -0.039 & $-0.211 * * *$ \\
Western region & & & & $0.143 * * *$ \\
Interval-ratio variable & 0.041 & $0.101 * * *$ & & $0.089 * * *$ \\
SES & & & & \\
\hline
\end{tabular}

$* * * \mathrm{p}<0.001 ; * * \mathrm{p}<0.01 ; * \mathrm{p}<0.05$ 
In particular, people in the Central region are not significantly different from their counterparts in Municipalities across all age groups. All these indicate that health status is somehow related to the macro social economic environment with stronger association among youth and adults other than seniors where biological aging takes more dominant role in health. Thirdly, social economic status has no significant impact on youth's health status, which indicates biological factor overcomes the impact of SES on health status.

\subsection{Health disparity by ethnicity}

When the pooled sample is divided into two subgroups by ethnicity (Table 5), we can see that, while all other variables affect both Han and Minority the same way, residence, survey year, and SES only affect Han people's health status significantly, which means the health status of minority groups in China is not differentiated by rural and urban, does not improve from 2005 to 2013, and does not change with their social economic circumstances. That is, if the health status can be used as a measure of life quality, Minority in China has not improved their living standard as much as Han group with the rapid social economic development between 2005 and 2013 in China, which could be an indication of unbalanced development or polarization of social wealth in China since the social and economic reforms in the 1980s. Moreover, when the ethnicity is controlled, the health difference between the Central region and municipalities is only significant for Minorities, not for Han group, and the situation is opposite between the Eastern region and the reference group, which indicates that the ethnic health disparity depends on regions where they live.

Table 5 The regression coefficient of variables on SRH by ethnic group

\begin{tabular}{lll}
\hline Variables & Han & Others \\
\hline $\begin{array}{l}\text { Categorical variable } \\
\text { Residential area (rural = ref) }\end{array}$ & & \\
$\quad$ Urban & $0.037 *$ & 0.036 \\
Region (municipalities = ref) & & \\
$\quad$ Northeast region & $-0.103 * * *$ & $-0.406 * * *$ \\
Central region & -0.044 & $-0.204 *$ \\
Eastern region & $0.194 * * *$ & -0.083 \\
Western region & $-0.127 * * *$ & $-0.435 * * *$ \\
Survey year $(2013=\mathrm{ref})$ & & \\
2005 & $-0.327 * * *$ & -0.082 \\
2008 & $-0.237 * * *$ & -0.102 \\
Interval-ratio variable & & -0.019 \\
SES & $0.090 * * *$ & \\
\hline$* * * \mathrm{p}<0.001 ; * * \mathrm{p}<0.01 ; * \mathrm{p}<0.05$ & &
\end{tabular}




\subsection{Health disparity between residential areas}

In Table 6, the total sample is divided into urban and rural sub-samples. It can be seen that only in the rural areas, the health difference between Han and Minority is statistically significant, which means more health equalization in the urban than in the rural which may be caused by much more health facilities available in the urban instead of rural area. Moreover, the regional health differences between urban and rural areas are more paramount. In the urban area, the poorer regions (Northeast and Western region) have a lower average health status than the one in the reference group and in the rural area, the significant health difference only exists between the Eastern region, a rich area, and the referent counterpart. That is, regional health disparity follows opposite patterns in urban and rural areas.

\subsection{Health disparity by marital status}

When the whole sample is classified into three groups based on the marital status (in Table 7), it is interesting to see that ethnicity and residence only affect the health status of those married in the same way as in the full model, and have no significant impact on those never married and ever married (separated, divorced, and separated). That is, while there is no significant difference among people with different marital status indicated in the full model, the health status of people with different marital status does be affected by different factors. Moreover, there no significant regional health difference among those ever married, and there is only significant regional health difference between Eastern region and Municipalities among those never married, while it follows the same pattern observed in the full model among those married. We may conclude that the health status of married people is influenced by more factors than those never and ever married.

\subsection{Health disparity by survey year}

Health status changes with time which is an indicator of the period effect. The impact of health determinants in different survey year is shown in Table 8. It is clear

Table 6 The ordinal regression coefficient of variables on SRH by residential area

\begin{tabular}{llc}
\hline Variables & Urban & Rural \\
\hline Categorical variable & & \\
Ethnic group (minorities = ref) & & \\
$\quad$ Han & -0.078 & $-0.121 * *$ \\
Region (municipalities = ref) & & \\
Northeast region & $-0.187 * * *$ & -0.005 \\
Central region & -0.061 & 0.040 \\
Eastern region & 0.054 & $0.340 * * *$ \\
Western region & $-0.169 * * *$ & -0.047 \\
\hline$* * * \mathrm{p}<0.001 ; * * \mathrm{p}<0.01 ; * \mathrm{p}<0.05$ & &
\end{tabular}


Table 7 The ordinal regression coefficient of variables on SRH by marital status

\begin{tabular}{lccr}
\hline Variables & Single & Married & Others \\
\hline Categorical variable & & & \\
Ethnic group (minorities = ref) & & & \\
$\quad$ Han & -0.036 & $-0.102^{* *}$ & -0.105 \\
Residential area (rural = ref) & & & \\
$\quad$ Urban & -0.043 & $0.048^{*}$ & 0.015 \\
Region (municipalities = ref) & & & \\
$\quad$ Northeast region & 0.024 & $-0.150^{* * *}$ & -0.036 \\
Central region & 0.099 & $-0.071^{*}$ & -0.062 \\
Eastern region & $0.203^{*}$ & $0.178^{* * *}$ & 0.126 \\
Western region & -0.053 & $-0.154^{* * *}$ & -0.172 \\
\hline$* * * \mathrm{p}<0.001 ; * * \mathrm{p}<0.01 ; * \mathrm{p}<0.05$ & &
\end{tabular}

that several variables have quite different effects on health status at different timing points. The ethnic health difference is only significant in 2005 favoring the Minorities and disappears in the following two surveys, which actually confirms the finding in Table 5 that the health status of Minorities has not been improved with time. Moreover, the residential health difference is only significant in 2008. Furthermore, the health status of those married is better than those ever married in 2005 and those never married have a better health status than the reference group in 2008, while no significant marital health difference in 2013. Lastly, the regional health difference varies with time. The health difference is only significant in 2005 between Northeast region and the reference group; it is significant in 2005 and 2008 between Western region and the reference group; it is significant in 2008 and 2013 between Eastern region and the reference group; it is significantly negative in 2005 and positive in 2013 between Central region and the reference group. That is, comparing to the

Table 8 The ordinal regression coefficient of variables on SRH by survey year

\begin{tabular}{llll}
\hline Variables & 2005 & 2008 & 2013 \\
\hline Categorical variable & & & \\
Ethnic group (minorities = ref) & & & \\
Han & $-0.201 * * *$ & -0.067 & 0.007 \\
Residential area (rural = ref) & & & \\
Urban & -0.055 & $0.135 * * *$ & 0.053 \\
Marital status (others $=$ ref) & & & \\
Single & 0.039 & $0.133 *$ & 0.031 \\
Married & $0.087 *$ & 0.033 & -0.011 \\
Region (municipalities $=\mathrm{ref})$ & & & \\
Northeast region & $-0.473 * * *$ & -0.032 & 0.063 \\
Central region & $-0.264 * * *$ & 0.006 & $0.082 *$ \\
Eastern region & -0.017 & $0.232 * * *$ & $0.280 * * *$ \\
Western region & $-0.297 * * *$ & $-0.154 *$ & -0.045 \\
\hline$* * * \mathrm{p}<0.001 ; * * \mathrm{p}<0.01 ; * \mathrm{p}<0.05$ & &
\end{tabular}


reference, the Municipalities, the average health status in all other regions is making more progress, which may be explained by more and more polluted natural living environment in those mega cities in China with time.

\subsection{Health disparity by region}

The impact of health determinants on the health status of people living in different regions is summarized in Table 9 with variables only having different effects. We can see that the ethnic health difference is only significantly different in Central region and Municipalities and the residential health difference is in favor of urban in Central region, but rural in Eastern region. Moreover, the SES has no significant impact on health in those two rich regions, Eastern region and Municipalities and positive impact in those three poor regions. It is clear that ethnicity, residence, and SES have varied impacts on the health status of people in different regions, which indicates that the macro social economic context does moderate the effect of health determinants included in this study.

\subsection{Health disparity by education level}

The impacts of health determinants on people with different education levels are shown in Table 10. We can see that, within four sub-groups with different education, ethnicity, residence, and region have different effects on the dependent variable. The ethnic health difference is significant in sub-samples with primary, middle, and high school education while the residential health difference is only significant in the subsample with no education. Moreover, the average regional health difference mainly exists among people with lower education levels (Uneducated and Primary/Middle school) following the same pattern observed in the determinant model and it gradually disappears among people with higher education levels (High school and College or higher), which indicates that the education level plays a very important role in health. That is, people with higher education level are doing well in health in spite of huge regional social and economic differences across China.

Table 9 The ordinal regression coefficient of variables on SRH by region

\begin{tabular}{llllll}
\hline Variables & Northeast & Central & Eastern & Western & Municipalities \\
\hline $\begin{array}{l}\text { Categorical variable } \\
\text { Ethnic group (minorities = ref) }\end{array}$ & & & & & \\
$\quad$ Han & 0.106 & $-0.194^{* * *}$ & -0.067 & -0.044 & $-0.272^{* * *}$ \\
$\begin{array}{l}\text { Residential area (rural= ref) } \\
\quad \text { Urban }\end{array}$ & 0.014 & $0.077^{*}$ & $-0.082^{*}$ & 0.040 & 0.088 \\
$\begin{array}{l}\text { Interval-ratio variable } \\
\text { SES }\end{array}$ & $0.170^{*}$ & $0.147^{* *}$ & -0.000 & $0.169^{* * *}$ & 0.041 \\
\hline
\end{tabular}

$* * * \mathrm{p}<0.001 ; * * \mathrm{p}<0.01 ; * \mathrm{p}<0.05$ 
Table 10 The ordinal regression coefficient of variables on SRH by education level

\begin{tabular}{lcccc}
\hline Variables & Uneducated & Primary/middle school & High school & College or higher \\
\hline Categorical variable & & & \\
Ethnic group (minorities =ref) & & & \\
Han & -0.102 & $-0.084^{*}$ & $-0.138^{*}$ & -0.026 \\
Residential area (rural =ref) & & & \\
Urban & $0.143^{* *}$ & 0.042 & 0.007 & -0.057 \\
Region (municipalities =ref) & & & -0.088 & -0.129 \\
Northeast region & $-0.283^{* *}$ & $-0.153^{* * *}$ & 0.060 & 0.009 \\
Central region & -0.084 & $-0.127^{* * *}$ & $0.139 * *$ & 0.015 \\
Eastern region & $0.210^{*}$ & $0.181^{* * *}$ & -0.068 & -0.127 \\
Western region & $-0.287^{* *}$ & $-0.170^{* * *}$ & & \\
\hline
\end{tabular}

$* * * \mathrm{p}<0.001 ; * * \mathrm{p}<0.01 ; * \mathrm{p}<0.05$

\subsection{Health disparity by income level}

The total sample is lastly divided into five sub-sample by income level, and the impacts of health determinants on people with different incomes are examined in Table 11. We can see that the ethnic health difference only exists among people with low income in favor of Minority. Moreover, only never married people with mid-high income have a better health than their reference counterpart. Furthermore, when income is controlled, people living in Northeast and Central region have similar health status with the reference group; the regional health difference is only significant among people with higher than middle income between Western region

Table 11 The ordinal regression coefficient of variables on SRH by income level

\begin{tabular}{|c|c|c|c|c|c|}
\hline Variables & Low income & Mid-low income & Middle income & Mid-high income & High income \\
\hline \multicolumn{6}{|l|}{$\begin{array}{l}\text { Categorical vari- } \\
\text { able }\end{array}$} \\
\hline \multicolumn{6}{|l|}{$\begin{array}{l}\text { Ethnic group } \\
\quad(\text { minorities }=\text { ref })\end{array}$} \\
\hline Han & $-0.138^{*}$ & -0.078 & -0.031 & -0.106 & -0.126 \\
\hline \multicolumn{6}{|l|}{$\begin{array}{l}\text { Marital status (oth- } \\
\text { ers = ref) }\end{array}$} \\
\hline Single & 0.132 & 0.005 & -0.065 & $0.160^{*}$ & 0.017 \\
\hline Married & 0.049 & 0.072 & -0.001 & 0.053 & 0.032 \\
\hline \multicolumn{6}{|l|}{$\begin{array}{l}\text { Region (munici- } \\
\text { palities = ref) }\end{array}$} \\
\hline Northeast region & 0.001 & -0.088 & -0.060 & -0.097 & 0.020 \\
\hline Central region & 0.060 & 0.059 & 0.003 & -0.052 & 0.048 \\
\hline Eastern region & $0.292 * *$ & $0.322 * * *$ & $0.268 * * *$ & 0.042 & $0.137 * * *$ \\
\hline Western region & -0.019 & 0.039 & -0.028 & $-0.214^{* * *} *$ & $-0.138 *$ \\
\hline
\end{tabular}

$* * * \mathrm{p}<0.001 ; * * \mathrm{p}<0.01 ; * \mathrm{p}<0.05$ 
and Municipalities; the regional health difference between Eastern and Municipalities is significant across most of the income groups. That is, comparing to people in Municipalities, those with the same income level are more likely to have similar health status in Northeastern and Central region, better health status in Eastern region, and worse health status in Western region.

\section{Discussion and conclusion}

Based on CGSS in 2005, 2008, and 2013, this study firstly examines the impact of demographic and socioeconomic factors on SRH status in China by using the ordinal complementary log-log model. We find that the health status in China varies with gender, age, ethnicity, residence, region, and socioeconomic status. We further explore the possible health disparity by checking whether these health determinants have different impact on the health status of sub-groups classified by the factors included in the determinant model. The main finding combining these two types of analyses can be summarized as following.

(1) When controlling all the other variables in the model, male's health is significantly better than female's in general. When male and female are examined separately, we find that male's health is more likely to be affected by social and cultural factors like ethnicity and marital status while female's is more likely determined by economic factors like residence and SES. We may conclude that the gender differential in health is the result of the interaction between biological and social, cultural, economic characteristics. Men and women have different expectations and roles in family and society, which have a significant impact on their health (Matthews 2015). China is still a country with a strong traditional value of men being superior to women and Chinese women often lack economic security, particularly in rural areas. Moreover, women in China normally have double burdens of working both inside and outside the household, which results in much more stress and pressure among women than men. The literature shows that Chinese women have a high suicide rate and prevalence of depression (Chen 2004). Furthermore, women, those in rural area in particular, are more likely to have reproductive health problems and less medical, health care and preventive health services, leading to inferior physical and mental health status compared to men (Mead et al. 2001; Vlassoff 2007). On the other hand, although the female life expectancy is longer than that of male, the SRH status of women is not higher than that of men because women are more sensitive to health issues and are more likely to report their health issues than men, which may result in a worse SRH status (Jiang 2006; Liu 2002).

(2) This study shows that the health status declines with age which could be simply the consequence of the biological aging process, which can be delayed by a healthy lifestyle, but cannot be avoided (Matthews 2015). While this negative relationship has not been moderated by other health determinants in the second session of analysis, some of these health determinants do affect people at different life course in different ways. With rapid population aging in China, health issues and health differences could be exacerbated with time. 
(3) The health status of Han people is lower than that of Minority in all circumstances considered in this research except in urban area, which is mainly because Han and Minority have quite different living environments, life style, culture, even genotype and so on. For example, most Minority people live in the specialized autonomous regions which are located in the remote or mountain areas, far away from large cities and they normally have their own traditional careers which have been passed on from one generation to the next for a very long time. Some of those minority groups have little contact with outside world which might explain why the health status of Minorities does not improve with time and socioeconomic status in China. Moreover, the ethnic health disparity is moderated by all health determinants included in the study, which means it depends on specific situations.

(4) There is significant health disparity between people living in urban and rural areas. Urban people always have a higher health status than their rural counterpart, which is consistent with the conclusion of Lowry and Xie (2009) and Zhao's (2005) study. This should be related to the unbalanced distribution of public and healthrelated facilities in particular in China with much better public health facilities in the urban area. Moreover, the rural area tends to have poor sanitation system, no necessary sport facilities and places for people to have leisure activities and exercise, have poor community integration and cooperation, and experience more violence (Zhao 2005). In addition, because of more and more strict environmental protection regulations in the urban area, almost all manufactures with toxic outputs are relocated in the rural area (Du and Ruike 2012), which makes the rural living environment much worse than the urban area. In the long run, equalizing the health disparity between urban and rural area not only contributes to the maintenance of fairness and justice, but also has important implications for coping with the deteriorating regional income equality.

This residential difference in health is moderated by all health determinants examined in this study except income. That is, the significant difference in health between urban and rural area varies with demographic factors and region. However, when income is controlled, this specific health disparity disappears. This can be explained by the reality in China that urban and rural have significant income difference (Ma 2016). Therefore, the health status of people with same income cannot be differentiated by residential area.

(5) Marital status has no significant effect on SRH in the determinant model and only single men have a better health status than those ever married counterpart, while previous research indicates significant marital differential in health in favor of those married people (Lillard and Waite 1995; Ross and Wu 1995; Umberson 1992; Wyke and Ford 1992; Waite and Gallagher 2000). The different conclusion in this study could be caused by the rapid demographic changes in current China like the delayed marriage and childbearing, fast rising divorce rate, and so on. Moreover, married people have more significant health disparity in terms of ethnicity, residence, and region than those ever married.

(6) As a whole, the health status increases with time in China with the exception of Minorities. Moreover, ethnicity, residence region, and SES have different impacts on health status in three survey years. For instance, the ethnic health disparity is only significant in 2005 and the residential health difference in 2013. The varied 
impact of health determinants across survey years indicates that the health issue is somehow time-dependent, an example of period effect.

(7) The regional health difference, in general, is somehow related to the regional social economic development level, lower in those poor regions and higher in those rich ones and it is moderated by all health determinants included in this study. As China has a state policy focusing on the economic development in the Eastern region at the beginning of economic reforms in the 1980s, the regional difference in economic development is being enlarged with time. Therefore, people from this area have the best health status because it has the best economic development, health facilities, and health care system. Moreover, when region is controlled, ethnicity, residence, and SES have different impacts on the health status of people in different regions. This tells us, region, as the macro living environment characterized by ethnic composition, geographic features, local habitat, lifestyle, customs, health facilities and health care system, economic development, social conditions, and so on, affects health status in a complex way which needs to pay much more attention in the future.

(8) In general, the SES is positively correlated with health status, which confirms the conclusion in the literature (Alvarez-Galvez et al. 2013; Deng 2010; Matthews 2015; Liu and Hu 2003; Xie 2009; Wang et al. 2004; Zhou and Duan 2013; Meara et al. 2008; Marmot et al. 1984; Kunst and Mackenbach 1994; Hou 2007; Zhao 2006; Li and Feng 2006), while we do find no significant association between SES and the health status of youth, minorities, and people in Eastern region and Municipalities. The common belief is that SES determines people's capability of investments in health, people's awareness of health, and related healthy behaviors and such, affects their health status in a straightforward manner (Cutler and LlerasMuney 2010; Ettner 1996; Feinstein et al. 2006; Mokdad et al. 2004; Shea et al. 1991; Brito and Noble 2014). When the whole sample is further divided by two proxies of SES, education and income, we find that both education and income can explain a lot regional health disparities. For example, the regional health difference disappears among people with high education and has been reduced a lot when income level is controlled.

Due to the limitation of the available information in the used survey data, this study can only focus on demographic and socioeconomic factors without examining factors like personal habit, living style, physiological and genetic measures. The further research can expand the study with a longer time range, more information, and different analytical methods, different subjective and objective health measures instead of SRH.

Health is the cornerstone of economic and social development, and the health of residents is important at both a micro and macro level. With the economic, medical, educational, and social developments, the overall health status of Chinese residents is getting better. However, the health disparity of the population has not been reduced in the same manner with the upper class of society deriving more "health benefits" from socioeconomic development, thereby widening the health gap between different classes (Franzini et al. 2001; Wilkinson and Pickett 2008). China is still in the middle of a significant transition with different development models for urban and rural areas which is likely to increase socioeconomic discrepancy, which 
highly correlates with health disparity (Hosseinpoor et al. 2012). The medical insurance system in China also has a much larger coverage in urban areas than in rural areas. As these inequalities expand, China's health disparity is gradually worsening (Wang et al. 2003; Zhang 2003). These China-specific factors make health disparity in China much different from any other countries. Therefore, it should be seriously taken into account in the future health-related public policies.

One important implication of this study is that, while economic situation plays an important role which should be paid enough attention, the health promotion and the maintenance of health equality should consider specific needs of different groups and those with low social economic status and rural area in health facilities and health care system in particular (Li and Feng 2006). In addition, the health status is association with both individual factors like gender, income, education, lifestyles and so on and macro social context like residential and regional differences in economic development, availability and accessibility of health facilities and health care system. Furthermore, in the twenty-first century, with the rapid population aging in China, the main health threat is becoming chronic diseases, which needs more healthy resources and advanced health techniques to deal with. Therefore, in order to improve general health status and health equality, China should propagate healthrelated knowledge, among those less educated people in particular and the healthy lifestyle as an investment.

Funding Funding was provided by Social Sciences and Humanities Research Council (SSHRC) of Canada (Grant no. 410-2007-1315).

\section{References}

Ahn, B. C., Engelhardt, K., \& Joung, H. (2010). Income-related health inequalities in Korea. Asia-Pacific Journal of Public Health, 22(1), 32-41.

Allen, S. M. (1994). Gender differences in spousal caregiving and unmet need for care. Journal of Gerontology: Social Sciences, 49(4), 187-195.

Allison, R., \& Foster, J. (2004). Measuring health inequality using qualitative data. Journal of Health Economics, 23, 505-524.

Alvarez-Galvez, J., Rodero-Cosano, M. L., Motrico, E., Salinas-Perez, J. A., Garcia-Alonso, C., \& Salvador-Carulla, L. (2013). The impact of socio-economic status on self-rated health: Study of 29 countries using European Social Surveys (2002-2008). International Journal of Environmental Research and Public Health, 10(3), 747-761.

Bai, J. (2008). Health equity from the perspective of life expectancy. People's Daily, 11, 6.

Barro, R. J. (1996). Health and economic growth. Washington, DC: Pan American Health Organization.

Braveman, P., \& Tarimo, E. (2002). Social inequalities in health within countries: Not only an issue for affluent nations. Social Science and Medicine, 54(11), 1621-1653.

Brito, N.H., Noble, K.G. (2014). Socioeconomic status and structural brain development. Front Neuroscience, 8, 276.

Burkhauser, R. V., \& Duncan, G. (1991). U.S. public policy and the elderly: The disproportionate risk to the well-being of women. Journal of Population Economies, 21, 217-231.

Chen, C. (2004). Ten year follow-up of China's nutritional status. Beijing: Beijing People's Medical Publishing House.

Cui, B., \& Li, W. (2009). Gender analysis of health, gender inequality and government health budgets. Population and Development, 15(1), 60-65. 
Cutler, D. M., \& Lleras-Muney, A. (2010). Understanding differences in health behaviors by education. Journal of Health Economics, 29(1), 1-28.

Deng, Q. (2010). Health inequalities in urban areas of China. Journal of Graduate School of Chinese Academy of Social Sciences, 5, 62-68.

Du, F., \& Ruike, W. (2012). Analysis and countermeasures of social determinants of health equity in the United States. Health Policy Research in China, 5(12), 34-39.

Elstad, J. I., \& Krokstad, S. (2003). Social causation, health-selective mobility, and the reproduction of socioeconomic health inequalities over time: Panel study of adult men. Social Science and Medicine, 57(8), 1475-1489.

Ettner, S. L. (1996). New evidence on the relationship between income and health. Journal of Health Economics, 15(1), 67-85.

Fan, Ming. (2002). Health effects on the performance of the labor market. Beijing: Social Sciences Literature Press.

Feinstein, L., Sabates, R., Anderson, T. M., Sorhaindo, A., \& Hammond, C. (2006). What are the effects of education on health? (pp. 171-354). Paris: OECD.

Ferro, K. F. (1980). Self-ratings of health among the old and the old-old. Journal of Health and Social Behavior, 21(4), 377-383.

Fogel, R. W. (1994). Population theory and physiology: The bearing of long-term processes on the making of economic policy. American Economic Review, 84(3), 369-395.

Franzini, L., Ribble, J. C., \& Keddie, A. M. (2001). Understanding the Hispanic health paradox. Ethnicity and Disease, 11(3), 496-518.

Gao, J., Qian, J., \& Tang, S. (2002). Health equity in transition from planned to market economy in China. Health Policy and Planning, 17(1), 20-29.

Grossman, M. (1972). On the concept of health capital and the demand for health. The Journal of Political Economy, 80(2), 223-255.

Hosseinpoor, A. R., Bergen, N., Kunst, A., Harper, S., Guthold, R., Rekve, D., et al. (2012). Socioeconomic inequalities in risk factors for non-communicable diseases in low-income and middle-income countries: Results from the World Health Survey. BMC Public Health, 12, 912.

Hou, J. (2007). Income hypothesis theory and health equity. Journal of Yunnan University of Nationalities, 24(1), 29-32.

Hu, L. (2005). Empirical study on income related health inequality in China. Health Economic Research, 12, 13-16.

Jiang, X. (2006). Analysis on equity in health for Chinese women with the gender view. Collection of Women's Studies, 4, 27-34.

Kunst, A. E., \& Mackenbach, J. P. (1994). Measuring socio-economic inequalities in health. Copenhagen: World Health Organization Regional Office for Europe.

Lee, M.-C., \& Jones, A. M. (2007). Understanding differences in income-related health inequality between geographic regions in Taiwan using the SF-36. Health Policy, 83, 186-195.

Li, Z., \& Feng, J. (2006). How education influences health: Base on surveys from Shanghai families. Chinese Labor Economy, 4(4), 15-31.

Li, R., Wang, W., Tan, J., \& Li, H. (2004). Health index and regional disparity of Chinese people. Human Geography, 19(3), 64-68.

Lillard, L. A., \& Waite, J. L. (1995). 'Til death do us part': Marital disruption and mortality. American Journal of Sociology, 100(5), 1131-1156.

Liu, Y. (2002). Concern: The survival of elderly women. Women of China, 2002(5), 18-19.

Liu, G. (2009). Health inequalities of residents in China and the development trend: Based on the CHNS 2006 health self-assessment data. Health Economic Research, 4, 21-23.

Liu, H., \& Chao, J. (2009). Analysis of income inequality and its influencing factors among urban residents in China. Chinese General Medicine, 12(9A), 1609-1610.

Liu, G., Dow, W. H., \& Fu, Z. (2004). The increases of income and human capital. Economy, 4(1), 101-118.

Liu, Y., \& Gu, H. (2011). Income-related health inequality of elderly people: Based on empirical study of Chinese urban and rural areas. Southern Population, 4, 1-9.

Liu, B., \& Hu, S. (2002). Health inequality research in the context of socioeconomic transition. Chinese Health Economics, 27(9), 7-8.

Liu, B., \& Hu, S. (2003). Empirical study on income related health inequalities. Health Economic Research, 1, 14-16. 
Liu, B., Jiang, F., \& Hu, S. (2006). Regional disparities in population health. China Health Resources, 9(1), 12-14.

Ma, X. (2016). The influence of urban and rural disparity on the health inequalities of urban and rural residents in China. City Problems, 11, 4-12.

Macintyre, S. (1997). The black report and beyond. What are the issues? Social Science and Medicine, 44(6), 723-745.

Maddox, G., \& Douglas, E. (1973). Self-assessment of health: A longitudinal study of elderly subjects. Journal of Health and Social Behavior, 14(1), 87-93.

Marmot, M. G., Shipley, M. J., \& Rose, G. (1984). Inequalities in death: Specific explanations of a general pattern? Lancet, 1, 1003-1006.

Matthews, D. (2015). How gender influences health inequalities. Nurse Times, 111(43), 21-23.

Mead, H., Witkowski, K., Gault, B., \& Hartmann, H. (2001). The influence of income, education, and work status on women's well-being. Women's Health Issues, 11(3), 160-172.

Meara, E. R., Richards, S., \& Cutler, D. M. (2008). The gap gets bigger: Changes in mortality and life expectancy, by education, 1981-2000. Health Affairs, 27, 350-360.

Mokdad, A. H., Marks, J. S., Stroup, D. F., \& Gerberding, J. L. (2004). Actual causes of death in the United States, 2000. JAMA, 291(10), 1238-1245.

Qi, L., \& Li, Z. (2011). Health and medical services utilization mobility. Economic Research, 9, 83-95.

Rao, K. (2004). Health inequity and its global trends. Chinese Hospital, 8(1), 35-38.

Ross, C. E., \& Wu, C. (1995). The links between education and health. American Sociological Review, $60(5), 719-745$.

Schoen, B. S., \& Weinick, R. M. (1998). Health-related behaviors and the benefits of marriage for the elderly persons. The Gerontologist, 38(5), 618-627.

Sen, A. (1980). Equality of what?, The tanner lecture on human values, delivered at Stanford University, May 22, 1979. In S. M. McMurrin (Ed.), Tanner lectures on human values (Vol. I). Cambridge and Salt Lake City: Cambridge University Press and University of Utah Press.

Shea, S., Stein, A. D., Basch, C. E., Lantigua, R., Maylahn, C., Strogatz, D. S., et al. (1991). Independent associations of educational attainment and ethnicity with behavioral risk factors for cardiovascular disease. American Journal of Epidemiology, 134, 567-582.

Sun, J., \& Song, Y. (2008). Health equity from the perspective of social gender: A survey of urban population groups in China. China Journal of Pharmaceutical Economics, 5, 19-27.

Umberson, D. (1992). Gender, marital status and the social control of health behavior. Social Science and Medicine, 34(8), 907-917.

United Nations Development Program (UNDP). (1990). Human development report. New York: Oxford University Press.

Vlassoff, C. (2007). Gender differences in determinants and consequences of health and illness. Journal of Health, Population, and Nutrition, 25(1), 47-61.

Wagstaff, A., Van Doorslaer, E., \& Watanabe, N. (2003). On decomposing the causes of health sector inequalities with an application to malnutrition inequalities in Vietnam. Journal of Econometrics, 112(1), 207-223.

Waite, L. J. (1995). Does marriage matter? Demography, 32, 483-507.

Waite, L. J., \& Gallagher, M. (2000). The case for marriage: Why married people are happier, healthier, and better off financially. New York: Broadway Books.

Wang, F. (2011). Social mobility will reduce health inequalities? Sociological Research, 2, 78-101.

Wang, F. (2012). Socioeconomic status, lifestyle and health inequalities. Society: Chinese Journal of Sociology, 32(2), 125-143.

Wang, Q., \& Liu, M. (2005). Health values and determinants. Economics, 5(1), 1-35.

Wang, X., Liu, J., Duan, Y., \& Xiao, Y. (2004). Study on the influence of income level of rural residents on health status in Ningxiang County. Chinese Health Economy, 23(4), 23-25.

Wang, L., Zhang, X., \& Coady, D. (2003). Health inequalities and the causes: An empirical study of China's child health survey. Quarterly Journal of Economics, 2(2), 417-433.

Wei, Z. (2004). The impact of health on non-agricultural employment and wage decisions. Economic Research, 2, 64-74.

Wilkinson, R. (1996). Unhealthy societies: The affliction of inequality. London: Routledge.

Wilkinson, R., \& Pickett, K. (2008). Income inequality and social gradients in mortality. American Journal of Public Health, 98(4), 699-704.

World Health Organization (WHO). (2016). World health statistics 2016: Monitoring health for the SDGs sustainable development goals (Annex B). Geneva: WHO. 
Wyke, S., \& Ford, G. (1992). Competing explanations for associations between marital status and health. Social Science and Medicine, 34, 523-532.

Xi, B., Zhou, C., Zhang, M., Wang, Y., \& Xu, L. (2014). Maternal and child mortality in China. The Lancet, 383(9912), 953-954.

Xie, E. (2009). Income-related inequality of health and health care utilization. Economic Research, 2, 92-105.

Zhang, C. (2003). Nutrition, health and efficiency: Evidence from poor rural areas in China. Economic Research, 1, 3-12.

Zhao, Z. (2005). Measuring health inequalities in China: Using self-rated health data. Chinese Labor Economics, 4, 14-35.

Zhao, Z. (2006). Health factors of country people in China. World of Management, 2(3), 78-85.

Zhou, J., \& Duan, D. (2013). Connotation and realization path of health equity among residents. Theory and Reform, 2013(6), 68-71.
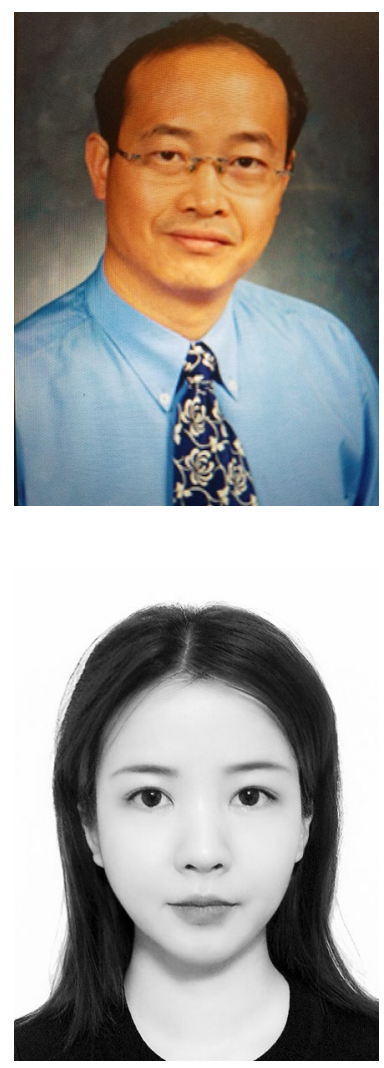

Jianye Liu obtained his BSc in Theoretical Physics from Lanzhou University, China, in 1988, MA in Demography from Peking University, China, in 1999 and PhD in Sociology, from UWO in 2004. He specializes in demography and quantitative research.

Yiqiao Zhang has a master degree in Sociology from Lakehead University. Her research interest is quantitative research in health and environmental issues. 